\title{
El deporte en el siglo XX: metrópolis, política y espectáculo
}

Conrad Vilanou *

No hay duda que por encima de otras posibles calificaciones, podemos considerar que el siglo $\mathrm{XX}$ ha sido el siglo del deporte. Con independencia de sus raíces clásicas que se remontan a la Grecia antigua, hay que decir que su recuperación se produjo en el siglo XX a través del ideario olímpico promovido por Coubertin a partir de la importación del modelo deportivo anglosajón a la Europa continental. Es evidente que durante el siglo pasado -es decir, el siglo XX- el deporte se ha convertido en un universal cultural que se ha extendido por todas partes. El ascenso continuo del movimiento olímpico -que reúne más estados que la mayoría de organismos internacionales- así lo confirma. Y aunque el deporte ha sido denigrado en más de una ocasión por situarse al servicio del poder político -el caso de la Olimpíada de Berlín (1936) es una buena prueba de lo que decimos-, no es menos verdad que el siglo XX -que ha asistido de manera impasible al desencadenamiento de dos Guerras Mundiales, sin olvidar el gran número de conflictos regionales que desgraciadamente todavía perduranpuede encontrar en el deporte una de sus aportaciones más positivas. Mejor que en el futuro recuerden el siglo XX por ser el siglo del deporte que no por la barbarie bélica, la bomba atómica de Hiroshima o las deportaciones que conducían a las cámaras de gas de Auschwitz.

El deporte entró en la cultura moderna con una clara vocación pedagógica porque, al margen de otras posibles lecturas, parece que tal como lo concibieron los educadores ingleses del siglo XIX tenía una función educativa que se quiso universalizar al destacar Coubertin la potencialidad de la Pedagogía deportiva (1922). En este sentido, no hay duda que el deporte -definido por el mismo Coubertin como "le cuite voluntaire et habitud de l'exercice musculaire intensif per le désir du progrès et ne craignant pas d'aller jusqu'au risque"-- ${ }^{1}$ constituyó, desde primera hora, un verdadero programa de regeneración social al proclamar valores modernos como el ejercicio físico, el gusto por el aire libre, la higiene y la camaradería, sin olvidar que el deporte era presentado como el mejor antídoto para combatir las plagas sociales (alcoholismo, enfermedades venéreas) que, en las postrimerías del siglo XIX, afectaban a la juventud. ${ }^{2}$

Además, bajo la influencia de los vientos neovitalistas el deporte promovió una plástica que -a la larga- fue utilizada por los regímenes totalitarios para favorecer la estetización de la política. Por otra parte, la aparición de los noticiarios cinematográficos facilitó la divulgación de las competiciones deportivas y el estudio a cámara lenta de las imágenes biomecánicas, que eran analizadas detenidamente en los laboratorios por fisiólogos y entrenadores a fin de mejorar la eficacia de los movimientos corporales (marcha, saltos, carreras, lanzamientos, etc.). A lo expuesto, hay que añadir que la divulgación del deporte comportó la extensión de una moral estoica que destaca la dimensión agonística del entrenamiento y de la competición deportiva. A pesar del peligro a las lesiones, el esfuerzo, el trabajo y la actividad desinteresada constituían algunas de las virtudes proclamadas por aquellos apóstoles nos referimos naturalmente a los pioneros que fundaron clubes y sociedades deportivas a fines 
del siglo XIX- que, un poco idealmente siguiendo una visión romántica de la tradición clásica, confiaban en la capacidad reformadora del deporte. Tanto es así que la exaltación de la lucha y del sacrificio fue presentada como un elemento clave para la formación humana de manera que se hizo famosa aquella expresión -a menudo mal interpretada pero que atesora una inequívoca voluntad pedagógica- que dice que lo más importante es, justamente, el hecho de participar practicando el juego limpio (fairplay). En último término, lo que forma es siempre la preparación para la competición deportiva al margen del resultado -positivo o negativo, derrota o victoriaque se da. Así entendía Thomas Arnold la formación deportiva de los universitarios británicos, aquellos que competían con los remos en las aguas del Támesis en las regatas entre Oxford y Cambridge o aquellos otros jóvenes que corrían en las pistas atléticas con el deseo de prepararse para la vida, tal como puso de relieve una película repleta de valores humanos como Carros de fuego (1981).

Con todo, no se puede perder de vista que en la Europa continental fue la gimnasia en primer lugar, y el ciclismo y el atletismo más tarde, los deportes que marcaron los mojones de un itinerario que se ha identificado con el paso de la gimnasia al deporte. ${ }^{3}$ Todo este cúmulo de circunstancias generó un proceso histórico que determinó el tránsito de la gimnasia -ejercicio típico del siglo XIX- al deporte que fue presentado por las vanguardias culturales y los manifiestos artísticos -y aquí el nombre de Dalí ocupa un lugar propio ya que su Manifest Groe (1928) así lo confirma- como un elemento innovador. El deporte en la época de entreguerras (1919-1939)- se identificaba con la innovación, la modernidad y el progreso, o lo que es lo mismo, con la vanguardia de una sociedad que deseaba romper los lazos con el estado de cosas anterior a 1914 que era percibido, además, como una cosa rancia y trasnochada. Estos antecedentes confirman el proceso de institucionalización del deporte que, a pesar de las manifestaciones elitistas de especialidades como la equitación, el golf, la esgrima o el tenis, llegó finalmente a todas las capas sociales. Añadamos, empero, un nuevo aspecto: la aparición después de la Primera Guerra Mundial (1914-1918) del deporte de masas -el fútbol, particularmente en Europa y por extensión en Latinoamérica- generó un fenómeno de nueva planta que con el tiempo había de recordarnos aquella cultura del espectáculo de la Roma imperial, es decir, el pan y el circo ya criticado por Juvenal en sus sátiras y combatido férreamente por el cristianismo primitivo (Tertuliano, Novaciano). ${ }^{4}$

Ahora bien, los acontecimientos políticos por los que ha transitado el siglo XX -el militarismo de los diferentes regímenes políticos autoritarios, el proceso de colonización de África y Asia que exigía una mejor preparación física, las campañas pseudocientíficas a favor de la desigualdad racial, la revolución soviética de 1917, la manipulación ideológica del deporte por el totalitarismo dictatorial, la guerra fría- han afectado la evolución del deporte que se ha convertido en un gran espectáculo controlado por las empresas mediáticas. De hecho, la televisión domina actualmente el mundo del deporte al imponer incluso cambios de reglas -la limitación de la duración de los partidos de tenis o la obligatoriedad de los tiempos muertos en el baloncesto- por razones de programación y exigencias publicitarias.

\section{El deporte, un fenómeno metroplitano}

Se ha de insistir que el deporte es un fenómeno típicamente moderno que se ha de vincular al crecimiento de las ciudades y a la aparición de un modelo de vida metropolitano. Stefan Zweig en sus memorias constata que en el siglo XIX no había triunfado todavía el deporte que cuajó con fuerza en el siglo XX. Zweig que se había formado en aquel mundo de la seguridad del imperio austría- 
co anterior a la Primera Guerra Mundial lo deja bien claro al manifestar que la lucha, los clubes de atletismo, los récords, a fines del siglo XIX eran cosas de barriada y su público era gente humilde y trabajadora. La aristocracia -como mucho- asistía a las carreras del hipódromo de Viena porque para la buena sociedad la actividad física significaba una absoluta pérdida de tiempo. ${ }^{5}$

Hubo que esperar a las primeras décadas del siglo XX para que el deporte constituyese un elemento más de la cultura metropolitana que había generado unas nuevas condiciones materiales y psicológicas de la población que, con el paso del tiempo, propiciaría la aparición de una categoría social desconocida y que deseaba romper con el mundo anterior: la juventud. Fue entonces cuando se asistió al crecimiento de las ciudades y a la mejora de las personas que se hicieron -al decir de un testigo de excepción como Stefan Zweig- más bellas y más sanas gracias al deporte, a una alimentación mejor, a una jornada de trabajo más corta y a un contacto más íntimo con la naturaleza. En medio de todo ello, las costumbres ciudadanas iban a experimentar un giro copernicano: nadie -a excepción de los más pobres- ya no se quedaba en casa los domingos ya que toda la juventud salía a caminar, a escalar y a jugar, practicando toda especie de deportes.

En esta dirección, el desarrollo de la cultura metropolitana -una manifestación típicamente moderna- contribuyó, al romperse los lazos que habían sostenido a la sociedad del Antiguo Régimen, la despersonalización de la vida humana que de esta manera entraba en el anonimato de la masa que favorecía la emergencia de sensaciones colectivas. Este conjunto de emociones multitudinarias fue manipulado políticamente por parte de los gobernantes que, asediados por las reivindicaciones obreras y temerosos que los estallidos revolucionarios, optaron por el camino del totalitarismo. La democracia -la historia de la República de Weimar (1919-1933) así lo demuestra- vivió un período de profunda inestabi- lidad durante aquellos años de crisis económica, política y espiritual. Este ambiente afectó negativamente al mundo del deporte que sufrió -después de la Primera Guerra Mundial- una contaminación militarista que influyó para que algunas prácticas deportivas adquiriesen un tono premilitar: el deporte -bajo regímenes dictatoriales como el fascismo italiano instaurado en 1922 y el nacionalsocialismo alemán asentado en 1933- se canalizó hacia la preparación para la guerra. Hay que añadir que en aquellos difíciles años de entreguerras las milicias -esto es, grupos de jóvenes armados que sembraban el terror por doquier- participaban violentamente en los asuntos políticos contando con la connivencia de los gobernantes de turno que veían en la juventud unas tropas de asalto que -en el caso del fascismo- habían de garantizar el orden social.

Desde un punto de vista urbanístico hacía tiempo que las plazas, las iglesias y los palacios -edificios propios del Antiguo Régimen- ya no eran los elementos que definían el espacio de una ciudad, sino las vías de comunicación -las nuevas calles trazadas geométricamente en forma de paralelas y diagonales- que habían de permitir el establecimiento de una rápida red de comunicaciones. Por ello un vehículo de transporte como la bicicleta se convirtió pronto en' un deporte proletario y, en consecuencia, profesional. Sólo los deportes típicamente burgueses y aristocráticos -con la inclusión de una especialidad universitaria como el rugby- defendieron el amateurismo más absoluto. Los trabajadores que habían abandonado sus ocupaciones para entrenarse intensivamente recibían cantidades económicas cada vez más elevadas como compensación de sus clubes que, en ocasiones, eran patrocinados por las mismas empresas, siendo el caso del Arsenal londinense un ejemplo ilustrativo de lo que decimos.

De hecho, los trabajadores necesitaban de un tiempo de ocio y disfrute que -de acuerdo con los planteamientos higiénicos del momento- 
habían de alejarlos de la taberna y del prostíbulo y llevarlos hasta las playas y montañas. Además, el paisaje urbano vio surgir la construcción de velódromo, pistas de patinaje, campos de fútbol, baños públicos y piscinas al aire libre. Aquellos gimnasios del siglo XIX -instalados en locales oscuros e insalubres- pasaban a mejor vida. Y en medio de este panorama de crecimiento de las ciudades aparecían los grandes estadios que, además de albergar las competiciones deportivas (atletismo, fútbol, etc.), serían utilizados para dar cobijo a todo tipo de grandes concentraciones políticas o religiosas. El estadio -al igual que el gimnasio en las polis helenísticas- se convertía así en un distintivo que marcaba el signo de la civilización de los tiempos modernos que culminaban en una cultura metropolitana que utilizaba la plataforma de las Exposiciones Universales para divulgar por todo el mundo las novedades deportivas.

Además, el deporte con su estética energética y vitalista alentaba una visión motorizada del cuerpo humano que fue presentada como un antídoto a los funestos efectos que se desprendían de una sociedad -heredera de la industrialización del siglo XIX- mecanizada. Efectivamente, el deporte -y aquí podemos incluir además del ciclismo, el motociclismo y el automovilismo- fue uno de los temas preferidos de los futuristas que al exaltar el dinamismo y la velocidad proclamaron la llegada de una forma de civilización que presentaba la obra de arte a manera de conjuntos plásticos en los que confluían los materiales y las substancias más dispares y los mecanismos más sorprendentes para producir nuevas sensaciones (luces, movimientos, ruidos). A pesar del desarrollo mecánico, el hombre metropolitano se encontraba encadenado a una dinámica opresora y asfixiante: su ritmo vital recuerda el ritmo de la producción industrial que se caracteriza por las combustiones y el funcionamiento de topo tipo de ingenios que circulan, sin cesar, en todos los niveles (superficie, cielo, subsuelo). Las ciudades se ven transitadas por grandes corrientes huma- nas -el hombre-masa se diluye en estas grandes riadas de gente- que se desplazan de un lugar a otro (en muchas ocasiones en ferrocarril metropolitano), situación que recuerda la imagen de la Babel bíblica en la que se convirtieron las concentraciones. Si el cine refleja perfectamente esta ambientación de elementos espectrales -a veces, casi fantasmagóricos- que dan vida a la metrópoli, tal como recogen películas emblemáticas como Metrópolis de Fritz Lang (1926) y Berlín, sinfonía de una gran ciudad de Walter Ruttmann (1927), no menor fuerza descriptiva poseen las crónicas periodísticas y literarias que narran cómo las masas proletarias se desplazaban -en muchas ocasiones tomando el "metro"- en las tardes de partido a los distintos campos de fútbol.

Talmente da la impresión como si los espectadores pareciesen mineros que saliendo del pozo -ésa es la imagen que recoge más de un escritor- se dirigen, después de una semana de duro trabajo, a tomar posesión en las gradas del estadio. Por lo común, el estadio se encuentra cerca de la estación del ferrocarril metropolitano. Las cifras que se reúnen pueden superar -nos referimos a la década de los años veinte- las treinta mil personas, treinta mil proletarios. Las bandas tocan marchas musicales de carácter popular. El sentido de tristeza y pobreza lo invade todo. Pero cuando salen los jugadores el público olvida sus penurias: el espectáculo comienza y la fiesta no puede desperdiciarse. El deporte y el fútbol por definición- se convierte en el opio de un pueblo que necesita hacer frente a las estrecheces de una vida humana que la industrialización tiende a robotizar y automatizar como reflejó ácidamente Charlot en Tiempos Modernos (1936): el hombre-máquina, el hombre-proletario, el hombre-masa, encuentra en la liturgia del espectáculo deportivo un canal para expresar catárticamente sus sentimientos y emociones.

Tampoco podemos olvidar que si la sociedad industrial del siglo XIX se hizo neosedentaria con 
el crecimiento de las ciudades, la sociedad metropolitana promovió una vida neonómada al aire libre. A través del descanso semanal -la famosa semana inglesa que aún explica, además de las razones puritanas, que los partidos de fútbol y de rugby se jueguen mayoritariamente en las islas británicas el sábado por la tarde- y las vacaciones -reivindicadas por los sindicatos y favorecidas por los gobiernos democráticos- permitió que las clases populares practicasen el excursionismo, la acampada o el turismo. Así se reencontró aquella naturaleza perdida que se rescataba románticamente como contrapunto a los excesos de la vida metropolitana y que, en la misma Inglaterra, promovió entre la juventud el escultismo de Baden-Poweel (1907).

\section{Nacionalismo y deporte}

A la hora de hacer consideraciones se puede decir que fue durante los años de entreguerras (1919-1939) cuando se impuso la idea de metrópolis, la ciudad a gran escala que -a más de simbolizar el progreso y la técnica- refleja una nueva naturaleza humana presidida por una masa anónima que camina absorta a través de un nihilismo que expresa, igualmente, desarraigo. El ser humano -al implantarse la vida metropolitanase encuentra extraño y forastero en su nuevo habitat, cosa que no ha de extrañar si tenemos en cuenta los grandes flujos migratorios que se produjeron del campo a las ciudades y de la Europa rural a las incipientes metrópolis americanas. Ahora bien, en aquellos mismos momentos los estadios iban a llenarse para dar cabida a grandes concentraciones de signo nacionalista que, de esta manera, aparecen como una afirmación de identidad y una actitud contraria a la aceptación -sin más- de ese mundo anónimo y atomizado en individuos aislados que promueve la vida metropolitana. De hecho, las manifestaciones deportivas de carácter nacionalistas hunden sus raíces en el siglo XIX, especialmente, en Centroeuropa. Tanto los turnen alemanes que los emigrantes trasladarán a América como el movimiento gimnástico de los sokols checos había alcanzado en el siglo XIX una gran difusión y predicamento. ${ }^{6}$ Ambos movimientos -es decir, la gimnasia germana y checa- poseían un sentido patriótico y militar que, a la larga, iban a oponerse frontalmente. Al pangermanismo de los turnen -fundados a comienzos del siglo XIX por Jahn en su deseo de combatir primero a Napoleón $\mathrm{y}$, más tarde, de extender la cultura alemana por toda la Europa central- respondieron los checos con un movimiento gimnástico -los sokols (halcones) habían sido fundados por Miroslav Tyrs el año 1862- que buscaba, a través de la disciplina gimnástica, luchar frente al expansionismo germano. Los sokols -con su gran estadio en Praga donde se reunían más de cien mil gimnastasiban a convertirse, después de la derrota de las tropas imperiales del Kaiser, en un ejemplo a imitar por buena parte de los movimientos nacionalistas europeos que luchaban por sus derechos histórico-geográficos a fin de encontrar un espacio en el mapa de la nueva Europa.

Bien mirado, la gimnasia de los sokols -que había preparado el terreno para la independencia checa- poseía alguna cosa de culto patriótico que sería proseguido por el nacionalismo xenófobo de los nazis. En efecto, las reuniones multitudinarias de los sokols fueron el preludio de las grandes manifestaciones nacionalsocialistas que siguieron el modelo de la reunión de Nuremberg de 1934, que dio pie al reportaje nazi El esfuerzo de la voluntad que deseaba transmitir a todo el mundo una estética paganizante de fuerza y vitalidad, impregnada de la exaltación de la raza aria. ${ }^{7}$ Por extensión esta estética plástica que reúne a miles de gimnastas, será adaptada por todas las fuerzas políticas dictatoriales (Alemania, Italia, Portugal, España, etc.) que anhelaban.como alternativa a los vicios de la vida metropolitana del liberalismo y a los valores revolucionarios del comunismo- un mundo disciplinado que, al no respetar los derechos fundamentales de las personas, comportaba un menosprecio hacia la 
dignidad humana. Por aquellos años se podía leer proclamas henchidas por una retórica pseudorevolucionaria: "Y vuelve el culto a la bandera, la algarabía entusiasta de los estandartes, el valor de los símbolos, el rito digno de los procedimientos, la emoción de los uniformes".

Lo que sucedió fue una cosa muy sencilla: el deporte se incorporó a la modernidad cuando justamente el mundo había perdido la seguridad de la sociedad tradicional. Toda una generación llena de energía e ideales se encontraba a la intemperie, tal como plasma.la literatura autobiográfica de aquellos jóvenes que padecieron las secuelas de Gran Guerra (1914-18). ${ }^{8}$ Tanto es así que el deporte se inscribe, por derecho propio, en un mundo metropolitano lleno de inestabilidades y en el que el individuo -desligado de los vínculos tradicionales- sale al encuentro de nuevas seguridades -de nuevos lazos sociales- que busca en el partido político, en el sindicato e, igualmente, en el asociacionismo deportivo. De esta manera, los clubes deportivos -con su iconografía específica- se inscriben en una lógica social que es inseparable a los avatares políticos y sociales, tal como confirma el hecho que los regímenes totalitarios expresasen -desde un primer momentoun desenfrenado deseo por intervenir y controlar cualquier tipo de agrupación deportiva. Con independencia de otros casos similares, la España franquista refleja perfectamente esta manipulación política que sitúa el deporte bajo la perspectiva del nacionalismo militarista: "En el Estado de la Falange, ser sano es una obligación y ser fuerte una virtud. El esfuerzo deportivo debe ser, como consecuencia, hecho con el pensamiento puesto en esta máxima y alejado en absoluto de toda idea de lucro, con la que tantos jóvenes malograron sus energías y agotaron sus músculos manejados y dirigidos por especuladores a la americana apartados por completo de las ideas de optimismo, salud y milicia".?

Mientras el desarrollo del deporte -sobre todo en la Europa occidental- se dio en un contexto histórico marcado por la expansión del nacionalismo, en las islas Británicas el deporte sirvió para revivir las antiguas guerras de religión y consumar la división de las comunidades católica y protestante. Esta situación -acentuada por la proximidad de Irlanda del Norte- todavía perdura entre los partidarios del Glasgow Rangers equipo protestante fundado el año 1873- y los Celtic Glasgow, integrado por católicos y que cuenta, desde su fundación en 1888, con el soporte de los emigrantes irlandeses. En este contexto, un conjunto de circunstancias -la incipiente profesionalización, la difusión del periodismo y de la prensa deportiva, la aparición de los primeros tópicos y mitos deportivos, sin olvidar la irrupción de la radio como elemento clave para las transmisiones deportivas- benefició la expansión del deporte. Al hilo de lo que decimos, deporte y nacionalismo constituyen un binomio que se remonta al siglo XIX cuando los yanquis después de la guerra de Secesión (1861-1865) utilizaron el deporte para despertar su espíritu nacional y fomentar un sentimiento colectivo de identidad. Es sabido que la ceremonia de izar la bandera y el canto del himno nacional forman parte de la liturgia deportiva. En realidad las grandes ligas (béisbol, fútbol americano, baloncesto, hockey sobre hielo) dan cohesión a un país inmenso formado por más de cincuenta estados. ${ }^{10}$ En el viejo continente europeo las cosas fueron diferentes pero no se puede negar que en un ambiente dominado por las teorías del darwinismo social y por las corrientes neomalthusianas que defendían la desigualdad entre los hombres (Gobineau) se vinculaba la práctica deportiva a la mejora de la raza, según los principios eugenésicos ya presentes en el sistema de vida espartano que se convirtió en el modelo a seguir por el nacionalsocialismo. No por azar Hitler aconseja en el Mein Kampf(1924) la práctica del boxeo como el mejor deporte para formar físicamente una juventud que se había de preparar para la lucha y que halló en los Juegos Olímpicos de Berlín (1936) una excelente oportunidad -tal 
como evidencia la película de Leni Riefenstahl Olympia- para propagar a todo el mundo su fortaleza y arrogancia. ${ }^{11}$

\section{Deporte burgués y deporte proletario}

Pero a pesar de que el nacionalismo todavía influye hoy sobre el deporte -las reticencias que encuentran algunas naciones sin estado para su reconocimiento por parte del Comité Olímpico Internacional (CIO) así lo pone de manifiesto-, no hay duda que la lucha de clases incidió poderosamente en la politización del deporte. El proletario -sobre todo socialista y comunista, ya que los anarquistas optaron por soluciones alternativas de talante radical como el nudismo, el culto al sol o una alimentación vegetariana- ${ }^{12}$ también comenzaron a practicar deporte. El hecho es incuestionable, aunque en un principio y contrariamente a lo que hacía la burguesía, los trabajadores cultivaron disciplinas duras y poco sofisticadas -el ciclismo, el fútbol, el atletismo, en especial carreras y marcha atlética-, modalidades que exigían pobres instalaciones y utillajes modestos. No se puede perder de vista que los primeros velódromos eran de tierra y que el ciclismo permitió a abrir pequeños talleres donde se alquilaban y reparaban bicicletas. Era frecuente ver como los mismos deportistas construían sus propias instalaciones a veces con más voluntad que acierto porque luego los terrenos de juego no cumplían las exigencias reglamentarias. Ello llegó a provocar situaciones conflictivas entre los clubes poderosos y los equipos más débiles económicamente que, en algunos casos, se independizaron de las federaciones a fin de organizar autónomamente sus propias competiciones. Además, el aire libre -ya fuese la montaña o la playa- servía para canalizar este tipo de iniciativas que se encuentran en la base de muchos clubes deportivos, algunos de los cuales todavía mantienen hoy su actividad.
Bajo los efectos de la Revolución Soviética de 1917 el mundo del deporte se escindió en dos grandes ámbitos contrapuestos que, de alguna manera, se mantuvieron estables hasta el año 1989 cuando cayó el muro de Berlín. De un lado, encontramos el deporte rojo o popular -en julio de 1921 se fundó en Moscú la Internacional Roja del Deporte- que practicaban las clases trabajadoras que tenían conciencia de su situación social y que, en ocasiones, no podían seguir el ritmo de las competiciones por el grado de profesionalización que habían alcanzado. Por otro lado, existía el deporte burgués que se identificaba con el movimiento olímpico internacional que mantenía una presencia significativa de miembros de la aristocracia y del ejército y que, inicialmente, se mostraba opuesto a la incorporación de las mujeres que no fueron admitidas en las pruebas de atletismo hasta los Juegos Olímpicos de Amsterdam (1928).

Además de negar su neutralidad y apoliticismo, el deporte proletario rechaza la dimensión excesivamente competitiva del deporte oficial y desea enaltecer, de acuerdo con los principios de la solidaridad internacional, los valores de amistad, participación y camaradería entre la juventud de todo el mundo. El movimiento obrero internacional -lejos de aspirar a una mejora constante de las marcas y los registros- destaca los aspectos lúdicos, festivos y cooperativos del deporte, confrontándolos con la lucha y emulación que comporta la práctica convencional de un deporte cada vez más competitivo y profesionalizado, sin olvidar las relaciones entre la cultura física y el compromiso político.

De aquí que frente a los Juegos que organizaba el Comité Olímpico Internacional apareciese el movimiento de las Olimpíadas Populares que tuvo una destacada influencia durante el período de entreguerras (1919-1939). Aunque sólo sea a título de anécdota, vale la pena recordar que el Estadio Olímpico de Barcelona lleva actualmente el nombre del presidente Lluís Companys, en 
recuerdo de la inauguración de la Olimpíada Popular que se inauguró en julio de 1936 en Barcelona y que, desgraciadamente, no se pudo llevar a cabo por la sublevación militar del general Franco. La ciudad de Barcelona había solicitado la organización de los Juegos Olímpicos de aquel mismo año que, finalmente, fueron otorgados a Alemania que bajo el mandato de Hitler aprovechó la ocasión con fines propagandísticos.

Es obvio que el deporte proletario -que se extendió especialmente entre los países de la órbita comunista, a pesar de que su influencia se dejó notar donde eran permitidos los sindicatos y las asociaciones obreras- ofrece una simbología propia y característica. Decimos esto porque, sobre la base que el deporte era un elemento eficaz para una política de unión de las fuerzas democráticas, se quería exaltar los valores de una juventud que trabajaba y que hacía deporte y que, con una voluntad pacifista, deseaba superar el ambiente de odio y beligerancia que había generado la Primera Guerra Mundial (1914-18). En los países comunistas como la URSS esta visión del deporte -que coincidía con una antropología que define al ser humano como un homo faber que ha de ejercitar sus habilidades físicas para acabar con la división entre trabajo intelectual y trabajo manualmagnifica la capacidad productiva que se manifiesta a través de los nombres de los clubes que aún hoy hacen referencia al potencial industrial (Dinamo, Torpedo, Lokomotive, etc.) o bien se identifica con la estrella roja de la revolución (Estrella Roja de Moscú, Belgrado, etc.). La consigna stalinista que la juventud se había de preparar para la defensa militar y la producción industrial se traslada al terreno deportivo, tal como hizo a partir de 1947, con mucho éxito, la República Democrática Alemana (DDR) que firmó con la URSS el Pacto de Varsovia, presentado a modo de alternativa defensiva a la OTAN. De todo lo dicho se desprende que el deporte permanecía al servicio del ideario revolucionario según las exigencias del modelo de un atleta con conciencia de clase, productor y soldado, que además manifiesta una vocación internacionalista.

Y todo ello bajo la influencia de aquella Esparta que no sólo influyó sobre el nacionalismo sino también sobre el comunismo que vio en aquella polis de ciudadanos iguales un modelo de austeridad y fortaleza físico-militar para la juventud. Tal atracción explica la existencia de diferentes clubes con este nombre (Sparta de Moscú, Sparta de Praga) que compiten todavía hoy a escala internacional. En este contexto, surgieron las Espartaquíadas -movimiento deportivo que reunía los practicantes de los países comunistas- por más que esta nomenclatura (que procede de Espartaco, el esclavo que se rebeló contra el imperio romano) recuerda el episodio revolucionario que surgió en Alemania al finalizar la Primera Guerra Mundial y que fue aplastado por la emergente República de Weimar (1919-1933).

\section{De la Guerra Fría a la mundialización del deporte}

El mundo que surgió después de la Segunda Guerra Mundial (1939-45) ya no era igual al de antes de 1939. De hecho, habían cambiado muchas cosas de manera que el deporte -una especie de religión laica que posee su propia organización y liturgia- adquirió una verdadera dimensión mundial. Las competiciones al más alto nivel -campeonatos continentales y mundiales- se extendieron sin cesar. La URSS se adhirió al Comité Olímpico Internacional el año 1951 y participó en los Juegos Olímpicos de Helsinki (1952). A pesar de las reticencias de la China comunista que, contraria a la presencia de la China nacionalista (Formosa), ingresó en el COI el año 1976, la verdad es que el deporte se convirtió en los años de la Guerra Fría en un instrumento -combatido desde la extrema izquierda, como veremos más adelante- para la coexistencia pacífica. 
Durante aquella época ciertamente tensa para la historia de la humanidad -situación que parece actualizarse hoy después de los atentados terroristas acaecidos en Nueva York el pasado 11 de setiembre de 2001-, se produjo un lento proceso de adaptación de los deportes a las nuevas condiciones -los deportes de sala- que facilitaban su práctica durante todo el año. Así el calendario ya no se reducía a una etapa estacional determinada -concentrada básicamente en los meses de verano- sino que se alargó con independencia de las condiciones climatológicas. Los deportes que hasta entonces se habían practicado al aire libre en velódromos, estadios, plazas públicas o pistas diversas pasan a ocupar lugares cerrados (indoor), a través de un proceso que siguieron después las piscinas, lo cual había de permitir la práctica de la natación durante el invierno favoreciendo que los niños aprendiesen a nadar. La sistemática construcción de Palacios de Deportes cubiertos a partir de mediados del siglo pasado obligó a adaptar las reglas de algunos deportes -el balonmano, es un buen ejemplo de lo que decimos- que, pocos años después de finalizar la Segunda Guerra Mundial, pasó de practicarse con 11 jugadores al aire libre a desarrollarse con 7 en instalaciones cubiertas. Tampoco podemos negar el beneficioso papel que empezó a ejercer la televisión a partir de la década de los años sesenta -como antes lo habían sido el cine y la radio- en la divulgación de una serie de deportes desconocidos para el gran público (hockey, voleibol, waterpolo, etc.).

Por su parte, la actitud de la Iglesia católica quizás un poco a remolque de lo que habían hecho las confesiones luteranas como el YMCA en cuyo seno habían surgido el baloncesto y el voleibol a fines del siglo XIX- se fijó en la importancia del deporte como instrumento de evangelización de la juventud. Además, se ha de destacar una actitud pontificia cada vez más favorable al mundo del deporte, circunstancia que se vio propiciada por el apoyo del Papa a los Juegos
Olímpicos de Roma (1960) y, poco después, por ia actitud aperturista del Concilio Vaticano Segundo (1962-65).

Hay que tener en cuenta, empero, que Europa había perdido su centralidad en beneficio de los Estados Unidos. Nueva York -diezmada hoy en su perfil por la caída de las torres gemelas- se convirtió en la capital del mundo en substitución de las ciudades europeas que poseían todavía estadios tan emblemáticos como el de Wembley en Londres o el del Parque de los Príncipes en París. Europa perdía protagonismo y América no sólo la del Norte sino también la del Sur con el estadio de Maracaná- se convertían en focos deportivos de primer orden. El fútbol hacía tiempo que triunfaba en Latinoamérica y los campeonatos del mundo celebrados en Brasil (1950), Chile (1962) y México (1970) confirmaron que el deporte se había convertido en un universal cultural que contaba, además, con nuevos ídolos como Garincha y Pelé.

Desde América del Norte -a través de les series televisivas y de las cintas cinematográficas- se divulgaban deportes inequívocamente americanos como el baloncesto y el béisbol, a la vez que se denunciaban las prácticas fraudulentas que rodeaban el mundo del boxeo. El sistema de vida americano se imponía por doquier mientras que los países situados bajo la órbita comunista -es decir, los que giraban en su condición de satélites alrededor de la Unión Soviética- seguían la concepción política comunista que, desde una perspectiva deportiva, negaba la existencia del profesionalismo que se ocultaba detrás de la burocracia civil o militar. Era una práctica común que los deportistas del Este de Europa -hombres y mujeres- ocupasen, para compensar sus éxitos, cargos de confianza en la estructura del estado, si bien esto no fue suficiente para frenar las deserciones de atletas a Occidente. Así ocurrió con el escandaloso caso de la gimnasta Nadia Comaneci que después de casarse con el hijo del presidente Ceausescu huyó a los Estados Unidos donde reside. 
Finalizada la Segunda Guerra Mundial en la que americanos y soviéticos habían sido aliados llegaba la hora de la Guerra Fría, del espionaje y de la carrera armamentista. Fue entonces cuando en 1961 se levantó el muro de Berlín y la lucha por el control del espacio se hizo patente. Mientras los soviéticos lanzaron en 1957 el Sputnik, el primer satélite artificial que les daba ventaja en la carrera astronáutica. Pero la reacción americana no se hizo esperar y doce años más tarde, en 1969, la tecnología americana ponía al hombre en la Luna. La fuerza física que había gozado de un gran prestigio antes de 1945 daba paso a una nueva situación geopolítica en la que el deporte se convertía en una manifestación de la excelencia de los respectivos sistemas políticos, cosa que ya se puso de manifiesto con la invasión de Hungría (1956) por las tropas soviéticas. Incluso, la victoria de España en la final del campeonato de Europa de fútbol -disputada en el estadio Santiago Bernabeu de Madrid el año 1964- ante la URSS, con un último gol de Marcelino, fue presentada por el régimen franquista como un triunfo del sistema político español -una "democracia orgánica" que dependía del autoritarismo dictatorial de Franco- frente al comunismo. Para la prensa del régimen franquista las cosas estaban claras: la "furia española" se había impuesto a la disciplinada maquinaria deportiva soviética.

La Guerra Fría se encontraba en el punto más álgido de manera que el escaparate de los Juegos Olímpicos había de servir para proclamar la conformidad o desacuerdo con determinadas decisiones políticas. Los boicots no se hicieron esperar y así diversos países -entre ellos España- renunciaron a participar en los Juegos Olímpicos de Melbourne (1956) a fin de expresar su disconformidad con los hechos de Hungría. ${ }^{13}$ Esta situación se prolongó -de una u otra manerahasta la caída del muro de Berlín porque si los americanos no concurrieron a los Juegos Olímpicos de Moscú (1980) por la ocupación soviética de Afganistán, como respuesta los soviéticos no estuvieron presentes en Los Angeles (1984).
A pesar de estas actitudes contrarias al espíritu olímpico que desea reunir a todo el mundo, no es menos verdad que el deporte también sirvió para desbloquear las relaciones entre ambos bandos. Así la "diplomacia del ping-pong", inaugurada en 1972, fue utilizada por chinos y americanos para establecer los primeros contactos entre ambas potencias. ${ }^{14}$

Por otra parte se produjeron en el contexto de la política internacional tres acontecimientos destacados: la revolución cubana (1959), el proceso descolonizador del tercer mundo y las campañas antiimperialistas. Es sabido que las colonias habían practicado -por simple imitación de las costumbres de la metrópolis- los deportes de la potencia colonizadora. De aquí la pasión del Japón -colonizado el siglo XIX por los americanoshacia el béisbol y de los hindúes -colonizados por los británicos- hacia el hockey sobre hierba. La revolución cubana ha utilizado -y de hecho continúa haciéndolo- el deporte como un aparador de las excelencias de un sistema político que fomenta con éxito la práctica deportiva entre la juventud. Hay atletas cubanos como Alberto Juantorena que se han convertido en verdaderos ídolos nacionales porque, siempre y en todo lugar, han mostrado su fidelidad a los ideales de la Revolución que ha sido a menudo traicionada por otros deportistas que han aprovechado cualquier viaje al exterior para solicitar asilo político. En cualquier caso, Cuba -a pesar del bloqueo que padece- lucha y combate ya no con la fuerza de las armas sino con el prestigio de sus atletas: una victoria ante Estados Unidos es mucho más que un simple resultado deportivo. La confianza en los ideales de la Revolución demanda una juventud que haga deporte y que contribuya a engrosar el palmares cubano que, de esta manera, constituye un ejemplo a seguir por los otros países del Tercer Mundo. A pesar de las dificultades que arrastran, los países en vías de desarrollo se pueden beneficiar de los planes de intercambio de técnicos y atletas que promueve el programa de Solidaridad Olímpica. Son bien recientes- 
las imágenes televisivas de deportistas (esquiadores, nadadores, etc.) que, sin dominar las técnicas respectivas, concurren a las competiciones internacionales donde evidencian las insuficiencias que padecen también sus países en materia deportiva.

En realidad el deporte había sido hasta hace pocas décadas una cosa reservada casi exclusivamente a la civilización occidental. Aunque en muchas ocasiones las tropas autóctonas parecían estar mejor preparadas que los soldados metropolitanos que tenían problemas para adaptarse a las condiciones de vida de la colonia, la verdad es que los atletas del tercer mundo no aparecieron en la escena deportiva hasta entrado el siglo XX. La presencia de atletas africanos en las reuniones atléticas internacionales es una exigencia imprescindible para garantizar buenas marcas. Hoy felizmente ya no es noticia que un atleta etíope o keniano gane una carrera atlética, aunque sí que lo sería si obtuviese un buen resultado en la prueba combinada del pentatlón moderno por las dificultades materiales y técnicas que comporta.

Por desgracia el mundo del deporte no ha quedado al margen de los actos de terrorismo. De aquí que la seguridad sea uno de los temas que más preocupan a los organizadores de los grandes certámenes deportivos que saben que se utiliza la plataforma de las competiciones para atentar contra los intereses de un determinado estado, situación que después de los últimos sucesos acaecidos en Nueva York puede repetirse en cualquier momento. Los atentados en los Juegos Olímpicos de Munich (1972) -año que asiste a la irrupción de los movimientos antiimperialistascostaron la vida a algunos miembros de la delegación judía y a los integrantes del comando palestino abatido por la policía: el deporte siempre es una buena atalaya para dar publicidad a cualquier reivindicación política sea del signo que sea. Y en ocasiones hay que añadir que los mismos organismos internacionales han favorecido este tipo de situaciones, polémicas y controver- sias. Es sabido que la FIFA dio la razón al gobierno militar de Pinochet -que había contado con el apoyo de un aficionado al fútbol como Henry Kissinger, secretario de estado de los Estados Unidos- cuando la Unión Soviética no quiso jugar un partido de fútbol en el mismo estadio en el que los golpistas chilenos habían ejercido la tortura. Esta situación de inestabilidad política y de falta de acierto en la toma de decisiones provocó una profunda crisis en el movimiento olímpico internacional que vio como una treintena de países africanos boicotearon los Juegos Olímpicos de Montreal (1976).

Es evidente que el movimiento de descolonización del tercer mundo y la lucha por los derechos de las minorías -en especial de los colectivos de raza negra de los Estados Unidos que, bajo las consignas del Black Power, utilizaron los Juegos Olímpicos de México (1968) para denunciar su marginación- habían generado, poco antes de su inauguración, importantes manifestaciones que denunciaban los gastos organizativos. A aquellas manifestaciones contrarias al gobierno mexicano -que se saldaron con el trágico balance de 250 muertos y 1000 heridos- siguieron las imágenes del reparto de medallas que recibieron Tommie Smith y John Carlos -primer y tercer clasificados en la prueba de los 200 metros lisos- cuando, con los puños recubiertos con guantes negros, mostraron su adhesión al Black Power. Incluso la conversión religiosa de Cassius Clay -oro olímpico en Roma (1960) y después campeón del mundo de los pesos pesados- y su incorporación al movimiento de los Musulmanes Negros (Black Muslims) hay que entenderlo más allá de la anécdota- dentro del contexto de la lucha por los derechos civiles y las campañas contra la segregación racial en un momento en el que en Sudáfrica se mantenía el apartheid a toda ultranza.

De manera lenta pero inexorable el deporte se ha abierto a todos los pueblos y culturas que 
hoy se han de afrontar con la intransigencia religiosa de determinados grupos integristas que limitan -e incluso prohiben- el deporte femenino. El rechazo del integrismo islámico -no confundir ni identificar con la civilización islámica- a los valores de la cultura occidental puede reportar una seria contrariedad para el mundo del deporte que -como es bien sabido-es una creación de la cultura griega. Atenas -y por extensión, todas las polis griegas- utilizaron el deporte como un simbolismo religioso $\mathrm{y}$, lo que también es destacado, como elemento de helenización. No hay que olvidar que Jeru-salén -y el mundo ortodoxo judío- se opuso en el siglo II a. C. a la presencia de gimnasios en Israel, desencadenándose la guerra de los Macabeos contra los griegos. Roma -síntesis de la cultura griega y hebrea a través del cristianismo- dio al deporte la dimensión de los grandes espectáculos del circo. Y si bien estos espectáculos fueron condenados por los Padres de la Iglesia y desaparecieron -no sin oposición- de la Ciudad de Dios (San Agustín), la verdad es que la Ciudad de los Hombres de la modernidad -que culmina como hemos visto anteriormente en el modo de vida metropolitano- acoge y difunde el deporte que triunfó, inicialmente, en los países de tradición cristiana, especialmente luterana. El deporte -una aportación cultural de la civilización occidental que constituye una nueva religión universal surgida sobre un pósito cristianismo- puede encontrar, en el siglo XXI, serios escollos en el mundo islámico que puede caer en la tentación de identificar el deporte con el imperialismo. Sea como sea, las relaciones entre deporte y religión van a constituir en los próximos años uno de los retos más destacados para todos aquellos interesados en la defensa y promoción de los valores deportivos.

Pero volvamos a la historia y veamos cómo a partir de la convergencia de una serie de factores -mayo del 68, reivindicaciones feministas, las marchas por los derechos civiles en los Esta- dos Unidos, el movimiento político de las panteras negras, las manifestaciones pacifistas contra la guerra del Vietnam, la lucha para abolir la discriminación racial, etc.- se generó una actitud hostil hacia el imperialismo americano y los modelos de vida capitalistas que promovían una visión del deporte excesivamente competitiva. Poco a poco cuajaron las teorías críticas que la sociología aplicó al deporte que así fue objeto de una profunda reflexión política. En este sentido, destaca el libro de Bero Rigauer que analiza la ideología del sistema de la competición deportiva que se asemeja a la ideología del capitalismo al destacar aspectos como el rendimiento, la voluntad de vencer y la disciplina en el entrenamiento. ${ }^{15}$

En este contexto, surgió la crítica freudomarxista (W. Reich) que vio en el deporte una sublimación de la fatiga y una práctica organizada del masoquismo puesto que el deportista goza con el dolor físico y el sufrimiento, a la vez que apaga la libido al neutralizar sus deseos sexuales. Desde esta perspectiva -que influyó en los cenáculos intelectuales próximos al mayo del 68se veía en el deporte una satisfacción substitutiva y represiva que constituye un nuevo opio para la sociedad que así permanece alienada. Algunas publicaciones francesas -en especial, la revista Partisans- ${ }^{6}$ dedicaron por aquella época artículos y números monográficos en los que se denunciaba que el deporte no sólo refleja las categorías ideológicas burguesas sino que también se encuentra mediatizado por el aparato burocrático del estado en el sistema comunista. Este tipo de literatura propició una importante corriente de sociología crítica en la que destaca el nombre de Jean-Marie Brohm que ha ensayado una sociología del deporte a partir del axioma que el deporte es política. Las obras de este autor que se difunden por Europa y América ponen al descubierto algunas de las contradicciones del deporte contemporáneo $\mathrm{y}$, por extensión, del movimiento olímpico internacional. ${ }^{17}$ En conjunto, estas críticas en- 
cuentran en el deporte todo un seguido de engaños que responden a los intereses del capitalismo: espíritu competitivo, especialización y división del trabajo, mecanización, alienación, afán mercantil, masificación, ceremonial fascista, manipulación política, etc. La respuesta no se hizo esperar desde el ámbito universitario en forma de un libro de Jean Meynaud Sport et Politique que, sin negar los vínculos entre ambos campos, destaca los aspectos positivos de la práctica deportiva siempre que reste al servicio del hombre. ${ }^{18}$ Desde la perspectiva de la teoría general de sistemas que aborda el mundo del deporte como un gran sistema que camina hacia la optimización, Elio Carravetta ha dado una solución a las aporías que plantea Jean Marie Brohm: al margen de las críticas -siempre pertinentes- el deporte atesora grandes posibilidades para la mejora del género humano. ${ }^{19}$

A su vez, los partidos de extrema izquierda opuestos a la tesis de los comunistas que defendían la coexistencia pacífica por medio del deporte- aprovecharon la ocasión para criticar duramente el deporte que, a su parecer, representa una actividad totalitaria al establecer unas claras relaciones de dependencia a través de unos mecanismos de orden y autoridad que reducen el cuerpo humano a un sistema cerrado de dominio y control. Vistas así las cosas, el deporte es el complemento idóneo para el trabajo mecanizado: el hombre que trabaja y hace deporte en su tiempo de ocio nunca se libera de la dependencia de la filosofía imperialista. De acuerdo con estos planteamientos que denuncian la pseudo-cultura (Adorno) y el hombre unidimensional (Marcuse), la intelectualidad progresista de los años setenta adoptó una actitud radical e iconoclasta contra el deporte. Sin embargo, hoy-como mínimo en España- nos encontramos con la paradoja que algunos de aquellos intelectuales contraculturales son colaboradores de la prensa deportiva, hecho que tampoco desautoriza la validez y actualidad de algunas de las críticas que se argumentaron en aquel momento.

\section{El deporte en la sociedad postmoderna}

El deporte moderno que nació en la Inglaterra del siglo XIX en un contexto pedagógico se encontró durante el siglo XX -desde el fin de la Primera Guerra Mundial hasta los Juegos Olímpicos de Los Angeles (1984)- bajo la dinámica de la política y la crítica ideológica. Aunque la cosa no ha cambiado de tendencia -da la impresión que el integrismo islámico ahora ha suplantado el papel que durante años representaba el comunismo-, lo cierto es que una vez concluida la Guerra Fría la dimensión política del deporte asume aspectos y características más sutiles pero no menos importantes. La prensa francesa -desde L'Equipe a L'Humanité- ha lanzado duras críticas contra la elección de Pekín como sede de los Juegos Olímpicos de 2008 -en detrimento de la candidatura de París- porque considera que la China ha de avanzar más en el proceso de modernización y democratización y, sobre todo, en la defensa de los derechos humanos. Pero para otros analistas la elección de Pekín ha sido un gran acierto al reconocer el papel de la China como potencia económica, política, militar y, finalmente, deportiva. Sin embargo, se espera que la celebración de los Juegos Olímpicos en Pekín para activar un programa de reformas democráticas.

Esta elección ha sido una de las últimas decisiones importantes de Juan Antonio Samaranch que, a pesar de las censuras que se han hecho a su gestión (presidencialismo, coopción de los miembros del COI, poca transparencia en la decisión de las sedes olímpicas, etc.), ha sabido renovar y reafirmar un movimiento olímpico que el año 1980 atravesaba una grave crisis. Se puede pensar que en estos últimos años -en especial a partir de la llegada de Samaranch a la presidencia del COI que encontró una gran ayuda en la política de Mikhail Gorbacov- el deporte ha entrado en el terreno de la lógica económica. Esto ha supuesto el fin del roman- 
ticismo, la aceptación de los atletas profesionales en los Juegos Olímpicos y la lucha de las cadenas televisivas por conseguir los derechos de las transmisiones deportivas.

En líneas generales, podemos decir que el deporte camina en los últimos años hacia un proceso de racionalización que tiene mucho que ver con el triunfo en la cultura occidental de una mentalidad pragmática de procedencia norteamericana, en la que todo se da de una manera prevista y controlada. Era el gran sueño de los positivistas del siglo XIX cuando con su lema de orden y progreso -presente en la bandera del Brasil- deseaban un mundo en el que la ciencia pudiese prevenir los acontecimientos. No había que dejar nada al azar. El mecanicismo de causa y efecto hacía posible un mundo geométrico y racional que, además, había de aplicarse a la realidad para que se obtuviesen unos resultados prácticos con criterio utilitario. Sólo basta observar el funcionamiento de los deportes típicamente americanos -el baloncesto es un magnífico ejemplo de lo que decimos- para percatarnos que responde a un reglamento minucioso, abierto continuamente a cambios y modificaciones, tal como corresponde a una sociedad dinámica que -desde la época de los Globetrotters- interpreta el deporte como un espectáculo que sintoniza con los valores de la sociedad capitalista en la que no se deja nada a la improvisación y en la que el tiempo -una inequívoca categoría de la economía capitalista- asume un poder absoluto. A su vez, se ha de añadir que el baloncesto -un deporte típicamente moderno surgido en 1891 en un ambiente puritano preocupado por la depuración de la violencia- sirve de ejemplo y paradigma para los otros deportes. Esta voluntad por limitar y censurar las transgresiones al reglamento coincide con las interpretaciones de Norbert Elias sobre el proceso de la civilización que ha generado históricamente normas de control de la violencia. ${ }^{20}$ Tanto es así que la limitación de las faltas personales se ha hecho extensiva, con el sistema de las tarjetas, a otros deportes que no con- templaban hace años la advertencia verbal, ni la amonestación previa a la expulsión.

Parece que el deporte que se había vinculado durante décadas a la esfera de la vitalidad y de la pasión'-es decir, a aquello irracional o poco racional, al mundo del inconsciente de las pulsiones y de los deseos- desea entrar por otras vías que responden a un esfuerzo de racionalidad que ha permitido iniciar la eliminación de las vallas metálicas en algunos estadios de fútbol. Hay que recordar que el fútbol es un deporte que tiene sus raíces en el violento juego medieval de la soule, vinculado a una tradición agraria que se confirma a través del léxico y de las expresiones que a menudo se utilizan. El fútbol -por ejemplo- es un deporte que se juega al aire libre, en contacto con la naturaleza, sobre una superficie que hay que cuidar con el talento de un campesino. Pero las cosas han cambiado en los últimos años y los nuevos estadios -per ejemplo, el Arena de Amsterdam- están cubiertos para hacer frente a las inclemencias meteorológicas. Cuatro gotas de lluvia no pueden ensombrecer un espectáculo televisivo patrocinado por una firma multinacional, tal como sucedió en el partido del centenario del Fútbol Club Barcelona que jugó con la selección de Brasil en la primavera de 1999.

A pesar de esta voluntad racionalizadora consubstancial a una política que quiere garantizar el éxito del espectáculo por encima de todo, la verdad es que menudean los actos violentos fomentados por el fenómeno hooliganism -la trágica final de la Copa de Europa de fútbol disputada en el estadio de Heysel (Bruselas) entre el Liverpool y la Juventus en 1985 así lo confirma- que expresa el espíritu de barbarie que para algunos autores ha aumentado a lo largo del siglo XX. ${ }^{21}$ Además, estas manifestaciones de agresividad y salvajismo colectivo se vinculan a un mundo de xenofobia y violencia. ${ }^{22}$ Sea como sea, se observa la tendencia que los espectadores tomen asiento en sus localidades puesto que la psicología ha postulado que la gente puesta en pie es más proclive a la violencia. 
Esta misma actitud racionalizadora y tecnificadora queda confirmada por la entrada del deporte en la Universidad como disciplina científica a través de los Institutos y de las Facultades de la Actividad Física y del Deporte. Hoy la investigación deportiva mueve muchos intereses de la industria farmacéutica, lo cual ha obligado a perseguir el doping hasta el extremo de crearse una Agencia Internacional que tendrá su sede en Montreal. Si hace unos años el deporte despertaba un buen número de disputas ideológicas, ahora el debate se ha situado en el ámbito de las controversias farmacológicas: la oportunidad y validez de los controles antidoping-tai como se constata en las últimas ediciones del Tour de Francia- parece ser lo que más preocupa.

Hemos de destacar que este proceso racionalizador -que será cada vez más sofisticado- ha sido posible porque el deporte se ha beneficiado del progreso científico que ha comportado la mejora de materiales e instalaciones, además de la presencia de aparatos de relojería extraordinariamente precisos. En pocos años se ha pasado de los cronómetros manuales a los registros electrónicos que permiten determinar las milésimas de segundo, cosa que promueve una pugna reñida por la mejora de marcas y récords. ${ }^{23}$ Incluso hay quien solicita la incorporación de los nuevos elementos tecnológicos para facilitar la labor de los arbitrajes -tema siempre controvertido- que, en ocasiones, se deja al buen criterio de una sola persona que en décimas de segundo ha de tomar decisiones que pueden malbaratar inversiones milionárias. Cuando alguien para defender este tipo de medidas unilaterales tomadas con prisa se escuda en el tópico que dice que "el fútbol es así", en realidad defiende una tradición en la que el azar \{alea, faturri) juega un papel importante y que, además, ha generado un mundo de apuestas nada despreciable. Pero la realidad confirma que el deporte ha entrado en la lógica de la competitividad, del éxito y la eficacia, esto es, del alto rendimiento de los centros especializados que trabajan con las mismas categorías que los institutos universitarios más avanzados: investigación teórica (biomecánica, psicología, bromatología, táctica, etc.) y aplicación práctica a las diversas especialidades deportivas.

El deporte ha acabado por convertirse en un tipo de vida que se identifica con el american way of Ufe. La moda se hace más deportiva, se persigue el mito de la eterna juventud, se impone una estética de cuerpos esbeltos y atléticos, a la vez que se exalta la velocidad y el riesgo. Todo este estado de cosas refleja algunos de los aspectos que configuran una cultura hedonista que, según el aforismo clásico del carpe diem, acepta el placer sin desdeñar el peligro en unas prácticas deportivas surgidas en las costas californianas y que encuentran en el vértigo -y en la sensación de suspenderse en el aire- la fuente de unas emociones que dan sentido a los modernos parques temáticos con sus atracciones de alta tecnología. Es lógico, pues, que el deporte también haya caído en la órbita de la racionalidad económica que, en una sociedad mediática y tecnológica, constituye uno de los núcleos más potentes de la industria del ocio: sólo el fútbol mueve en el estado español un billón de pesetas cada año, cifra que corresponde al 0,9 de PIB.

Deporte y turismo -ámbitos que se encuentran unidos no sólo en los deportes de invierno sino también en los deportes de aventura y en las actividades físicas en la naturaleza- son valores emergentes en los mercados económicos. Podríamos decir que hoy el deporte es un sector de negocios que, de acuerdo con la lógica postmoderna, oscila entre lo real y lo virtual. En efecto, los ingresos del deporte no provienen tanto del público que asiste en directo a las competiciones como de los derechos televisivos, sin descuidar tampoco el capítulo de los ingresos atípicos que se generan. Al fin de cuentas, la televisión es la gran fuente económica del deporte, cosa lógica si consideramos que nos encontramos en una sociedad en la que todo se hace espectáculo, y más concretamente, espectáculo doméstico. Así pues, la pro- 
ducción televisiva se configura como el instrumento más eficaz para la construcción social del deporte que alcanza una clara dimensión ideológica. En efecto, la sintaxis televisiva construye una semántica propia, una trama histórica y narrativa que sirve para canalizar unos contenidos emocionales y culturales que desbordan con mucha facilidad el contexto del paradigma deportivo tradicional. $^{24}$

Gracias a la fuerza del discurso televisivo -y su correspondiente dinámica carismática del ciclo competición, conquista, coronación- se fomenta una identificación colectiva que comporta significaciones simbólicas que se han de enmarcar en el contexto de los conflictos y de las construcciones políticas. En esta dirección, la narración televisiva ofrece una inequívoca dimensión política que sirve para exaltar la épica del estado-nación (todavía se recuerda la entusiasta actitud del presidente Sandro Pertini en la final del Mundial de Fútbol de 1982 en un momento difícil para la política italiana pocos meses después del asesinato de Aldo Moro) o bien per magnificar, especialmente cuando el éxito de les selecciones nacionales no acompaña, la significación de los triunfos deportivos de determinados clubes (Bayern Munic, Real Madrid) que, después de ganar la Champions League europea en las últimas ediciones, se identifican con el orgullo nacional de sus respectivos estados en un momento histórico en el que su protagonismo se diluye en medio de los vientos europeístas que impondrán -a partir del 1 de enero de 2002- una única moneda (euro) en el viejo continente.

De acuerdo con esta lógica del espectáculo televisivo, hoy día ya no son los clubes deportivos -transformados en opulentas sociedades anónimas que cotizan en bolsa- los que necesitan las grandes cadenas de televisión sino, justamente, al contrario: son las multinacionales de la comunicación las que dependen de los grandes clubes y de los acontecimientos deportivos (Juegos Olímpicos, campeonatos mundiales, etc.) a fin de asegurar los índices de audiencia y garantizar así los ingresos derivados de la publicidad. $\mathrm{Y}$ aunque el intervencionismo político no ha desaparecido del todo, después de la caída del muro de Berlín (1989) hemos asistido a la irrupción de una razón económica -medios de comunicación, canales de televisión, empresas de ropa deportiva, bebidas refrescantes, industrias tabaqueras, sector del automóvil, etc.- que a través de la sponsorización controla este gran negocio que mueve millones y millones de dólares y que entra en la lógica del espectáculo de una sociedad mediatizada por la televisión. Si todo lo que no aparece en la televisión no existe, el deporte que permanece al margen del circuito de los medios de comunicación -el deporte escolar, el deporte amateur, el deporte para todos, los deportes minoritarios, el deporte ocio, el deporte de los discapacitados, el paraolimpismo, etc.- ocupa un lugar irrelevante en el panorama deportivo. La prensa y los programas de radio y televisión ahora ya existen canales temáticos dedicados al deporte y a clubes en exclusiva- confirman esta tendencia. Mientras unas noticias deportivas circulan por todos los canales hay otras que nunca afloran a los primeros planos. Si las cosas son así es congruente que el deporte sea un gran escaparate publicitario que genera elevados beneficios económicos y que, a su vez, legitima gobiernos que aprovechan la oportunidad de las grandes competiciones deportivas para promover el turismo y justificar -éste fue el caso de la dictadura Argentina con la organización del Campeonato del Mundo de fútbol de 1978 y puede ser el caso de los Juegos Olímpicos de Pekín (2008)- sus respectivos sistemas políticos.

Definitivamente el deporte ha entrado en el terreno de la lógica postmoderna de la economía neoliberal de manera que aquel halo romántico de otro tiempo -cuando se confiaba en una serie de valores como el esfuerzo desinteresado, la superación personal, el respeto al contrario y la magnanimidad del vencedor- ha desaparecido, o en su caso, ha quedado limitado a ámbitos muy 
restringidos. Probablemente sea en el campo deportivo donde con más fuerza han triunfado los valores postmodernos, cosa que no ha de extrañar si consideramos que el deporte es una realidad moderna que creció en la sociedad metropolitana y alcanzó su madurez en una cultura que se ha hecho hipermoderna. ${ }^{25}$ Desde aquí la postmodernidad no es otra cosa que un estadio evolutivo de la misma modernidad, una especie de alta modernidad que puede eidenticarse con la hipermodernidad.

Al fin de cuentas, el deporte se ha adecuado a un nuevo contexto que ya no se corresponde con la idea del cuerpo-máquina (modelo que sirvió para desarrollar el discurso gimnástico durante el siglo XIX), ni con el modelo del cuerpo energético y motorizado (que corresponde a la explosión social del deporte a comienzos del siglo XX), sino con la idea de un cuerpo virtual a manera de un verdadero organismo cibernético (cyborg) que, bajo la presión de la publicidad, se puede modular a través del ejercicio físico, de la cirugía, de la ingeniería genética y de la tecnología: hoy nos encontramos más cerca que nunca de un cuerpo humano que se puede convertir en un mecanismo de alta tecnología cibernética. La última película de Steven Spielberg A. I. Inteligencia Artificial (2001) revive con sus hombres-orgy los robotsmeca un tema ya clásico de la historia del cine: el sueño de la construcción de un robot ya presente en Metrópolis (1926), transformado un replicante en Blade Runner (1986) y reconvertido ahora en un robot-meca que busca -al igual que los seres humanos- amar y ser amado. En cualquier caso, esta visión postorgánica, que tiende a convertir los cuerpos humanos en replicantes de modelos publicitarios y a los jóvenes deportistas en copias de sus ídolos -la cultura postmoderna se sirve del simulacro y de la imitación virtual-ha desencadenado un nuevo discurso corporal que está influyendo sobre la estética, la moda y las ciencias sociales y que, a su vez, constituye uno de los grandes retos que ha de asumir la cultura del siglo XXI. ${ }^{26}$
Es hora de acabar y de recordar que Lyotard señala en La condición postmoderna (1979) que ante la dificultad de distinguir entre la verdad o falsedad de las proposiciones, sólo nos queda la solución de la eficacia (performatividad). Este planteamiento utilitarista sirve para ilustrar el camino que ha escogido el deporte en el último tramo del siglo XX: la mitificación de la marca y del récord, el afán desmesurado de victoria, esto es, del éxito personal y colectivo de unos deportistas que necesitan del triunfo -al margen de los mecanismos que se han empleado para conseguirlopara continuar gozando de las ventajas económicas que conceden los sponsors y las cadenas de televisión. En ocasiones da la impresión como si la ética deportiva (elfairplay) nos hubiese abandonado para siempre porque la victoria -aquella nike clásica transmutada ahora en multinacional deportiva- es la que guía todos los objetivos: participar ha pasado a mejor vida, sólo preocupa ganar. En último término, el espectáculo -y el deporte es el gran espectáculo de una sociedad postmoderna, mediatizada y globalizada- sólo se interesa por los vencedores. El resto, simplemente, no existe.

\section{Notas}

i $p_{\text {Cerre }}$ ¿e Coubertin, Pedagogie Sportive, París, Librairie Philosophique J. Vrin, 1972.

${ }^{1}$ Para una lectura actual del deporte y del olimpismo desde la perspectiva pedagógica, se pueden consultar las obras Olimpismo y Fair-Play (Ayuntamiento de Murcia, 1999) y La Educación Olímpica (Ayuntamiento de Murcia, 2000).

3 Jacques Ulmann, De la gymnastique aux sports modernes, París, Librairie Philosophique J. Vrin, 1989.

Una edición reciente de los textos de Tertuliano y Novaciano se puede encontrar en De Spectaculis. 
Ayer y hoy del espectáculo deportivo, Madrid-Las Palmas, Ediciones Clásicas-Universidad de Las Palmas, 2001.

5 Stefan Zweig, El món d'ahir. Memòries d'un europeu, Barcelona, Quaderns Crema, 2001, p. 81.

${ }^{6}$ Diethelm Blecking (Hg.), Die slawische Sokolbewegung. Beitráge zur Geschichte von Sport und Nationalismus in Osteuropa, Dortmund, Forschungsstelle Ostmitteleuropa, 1991.

${ }^{7}$ Wolfgang Weber, Von Jahn zu Hitler. Politik und Organisationsgeschichte des Deutschen Turnens in Vorarlberg, 1847-1938, Konstanz, Universitätsverlag Konstanz, 1995.

${ }^{8}$ Ernst Toller, Una joventut a Alemanya, Barcelona, Edicions de 1984, 2001.

9 "El deporte en el estado nacional sindicalista", Vértice, núm. 10, mayo 1938.

DonaldJ. Mrozek, Sport and American mentality, 1880-1910, Knoxville, The University of Tennesee Press, 1985.

${ }^{1}$ Hago Bernett, Der Weg des Sports in die nationalsozialistische Diktatur, Schorndorf, Karl Hofmann, 1983.

${ }^{12}$ Poco después de la Primera Guerra Mundial, el socialismo y el comunismo iniciaron, cada uno por su lado, dos movimientos internacionalistas para promover la práctica deportiva entre la juventud trabajadora (André Gounot, "Eis origens del moviment esportiu comunista a Europa", Acacia, 4, 1995, pp. 75-99).

${ }^{13}$ Conocidos son los incidentes del partido de waterpolo jugado entre las selecciones de Hungría y la URSS que reflejó en la piscina australiana la oposición húngara a la invasión soviética. Finalmente Hungría ganó aquel partido y el oro olímpico al imponerse a la URSS por un contundente 4 a 0.

${ }^{14}$ En relación a las implicaciones políticas de los Juegos Olímpicos se pueden consultar - entre otras - las siguientes obras: Richard D. Mandell, Historia cultural del deporte, Barcelona, Edicions Bellaterra,
1986 y Juan Rodríguez López, Historia del Deporte, Barcelona, Inde Publicaciones, 2000.

${ }^{15}$ Bero Rigauer, Sport and work, New York Columbia University Press, 1981.

${ }^{16}$ Partisans, Deporte, cultura y represión, Barcelona, Gustavo Gili, 1978.

${ }^{17}$ Entre las obras de J. M. Brohm citamos: Le mythe olympique, París, Ch. Bourgois, 1976; Critiques du sport, París, Ch. Bourgois, 1976; Sociologia política del deporte, México, Fondo de Cultura Económica, 1982 y Materiales de sociología del deporte, Madrid, La Piqueta, 1993.

18\%. Meynaud, El deporte y la política, Barcelona, Hispano-Europea, 1972. Es evidente que a partir de los años setenta han proliferado los libros que abordan el deporte desde una perspectiva política: Luis $M^{a}$. Cazorla Prieto, Deporte y estado, Barcelona, Labor, 1978; J. M. Hobermnan, Politica e sport. II corpo nella ideologia deli' 800 e del 900, Bologna, 11 Mulino, 1988; Ph. Simonnot, Homo Sportivus. Sport, capitalisme et religión, París, Gallimard, 1988, etc.

${ }^{19}$ Elio Carravetta, O Esporte Olímpico: um novo paradigma de suas relações sociais e pedagógicas, Porto Alegre, Editora da Universidade Federal do Rio Grande do Sul, 1997.

${ }^{20}$ TV. Elias, El proceso de la civilización, México, FCE, 1987.

${ }^{21}$ Erich Hobsbawm, "La barbarie de este siglo", Debats, 50, 1994, pp. 30-37.

$22 \quad$ N. Elias i E. Dunning, Deporte y ocio en el proceso

de la civilización, México, Fondo de Cultura Económica, 1992.

${ }^{23}$ Una de las grandes diferencias entre el deporte clásico y el moderno radica, justamente, en este punto. Los griegos - a pesar de poseer relojes de arena y aguano demostraron interés por establecer marcas. El atleta griego buscaba la victoria (nike) a fin de alcanzar una fama que perdurase su gloria más allá de la muerte. De alguna manera el atleta griego perseguía - al igual que Aquiles - la inmortalidad 
que, en una cultura oral como la helénica, sólo se podía obtener a través del canto poético (Píndaro).

${ }^{1}$ TV. Porro, «L'esport televisat, entre espectacle $i$ comunicado política», Revista Catalana de Sociologia, 5, 1997, pp. 87-116.

Jacques Gleyse, L'instrumentalisation du corps. Une archéologie de la rationalisation instruméntale du corps, de l'Age classique à l'époque hypermoderne, París, Editions L'Hartmattan, 1997.

Haraway, D. ]., Ciencia, cyborgs y mujeres. La reinvención de la naturaleza, Madrid, Cátedra, 1995.

* Conrad Vilanou é professor da Universitat de Barcelona e-mail: cvilanou@d5.ub.es 